\title{
It's Not Just About Attention to Details: Redefining the Talents Autistic Software Developers Bring to Software Development
}

\author{
Hala Annabi \\ The Information School, \\ University of Washington \\ hpannabi@uw.edu
}

\author{
Karthika Sundaresan \\ The Information School, \\ University of Washington \\ karthika@uw.edu
}

\author{
Annuska Zolyomi \\ The Information School, \\ University of Washington \\ annuska@uw.edu
}

\begin{abstract}
Technology giants SAP, Google and Microsoft have recently begun hiring initiatives targeting individuals with Autism Spectrum Condition (ASC) for software development roles. In order to fully engage and include individuals with ASC, a deeper understanding of the cognitive style and talents of individuals with ASC is needed. In this paper we present an analysis of current cognitive theories of autism, and promote the theory of hyper-systemizing as one that best explains the talents and challenges that surface in ASC. We compare the talents of individuals with ASC to skills required of software developers and identify synergies between the developer skills and strengths of individuals with ASC, such as systemizing, information processing, and specialization of interests. Our analysis concludes with a synthesis of the strategies necessary to create inclusive workplaces that promote the professional development of individuals with ASC.
\end{abstract}

\section{Introduction}

With the rising prevalence of Autism Spectrum Condition (ASC), coupled with the unmet employment demands of the technology industry, there is increased effort to connect high functioning individuals with ASC with jobs in the technology industry $[2,7]$. Leaders in this effort are smaller firms like Specialisterne [7], which later informed employment programs of technology giants SAP, Google and Microsoft [2; 19]. These companies stated social responsibility and business benefits as two drivers for their initiatives to hire and onboard individuals with ASC $[2,19,31]$.

From a social responsibility perspective, champions of such programs point to the growing number of individuals with ASC and the challenges the population faces in securing meaningful employment $[3,7,28]$. A recent longitudinal study found that only $58 \%$ of young adults (21-25) with ASC were employed for pay, compared to $99 \%$ of neuro-typical young adults [25]. In fact, the report suggests that overall, individuals with ASC face higher barriers in securing employment or pursuing postsecondary education compared to all other groups of young adults who enrolled in special education services while in high school [28, 25]. Even when employed, individuals with ASC face discrimination and isolation in the workplace $[19,6]$. Motivated by these social challenges, a few individuals who have children on the autism spectrum created technology firms (Specialisterne and Aspiritech) that hire and integrate individuals with ASC in technology roles [7, 2].

Following suit, larger technology firms like SAP, Microsoft, and Google initiated similar employment programs as they recognized not only the social impact such programs could make, but also the potential benefits of hiring individuals with ASC [2, $19,7]$. Tech companies and scholars from various fields recognized the leanings of individuals on the spectrum to pursue technical interests [17]. For example, a recent national longitudinal study revealed that individuals with ASC are more likely to pursue and persist in STEM fields in postsecondary education than non-STEM fields [32]. This, along with initial success from companies such as Specialisterne at hiring individuals with ASC, emphasized the potential business benefits of hiring individuals with ASC. Tapping into the unemployed or underemployed ASC population provides an opportunity for technology companies to meet the rising demand for technology workers. Furthermore, technology companies benefit from the unique talents of employees on the autism spectrum, such as attention to detail, high level of focus, comfort with doing repetitive behavior, and ability to visualize problems $[2,19]$. 
The early programs and studies of employing individuals with ASC in technical roles stressed the importance of the population's unique abilities to focus on detail and comfort with repetitive tasks [2, 19, 17]. In particular, scholars and champions of ASC technical employment programs stressed that developers with ASC possess cognitive skills especially suitable for certain roles in the technology industry [2]. These scholars and practitioners suggest that individuals with high functioning autism (HFA) are especially skilled, even more capable than neurotypical developers, at paying attention to detail, detecting error, and orderly coding (e.g. $[2,19,17])$. They suggest that these cognitive capabilities make developers with ASC especially suited for software testing, quality control, and security work [2].

While we agree that these talents of attention to detail, high level of focus, and ability to focus on repetitive tasks are possessed by some developers on the autism spectrum and fulfill important roles in the industry; they are not the full extent of the depth of talents that these individuals bring to the technology industry. These surface level talents of individuals with ASC are merely aspects of a higher level cognitive style capable of drawing and detecting patterns and rules in the context of complex systemizing [4]. Rather than focusing solely on the surface level talents of individuals with ASC, an approach that capitalizes on the underlying cognitive styles of ASC will enable individuals with ASC and employers to more holistically apply their talents.

The purpose of this paper is to further develop our understanding of the cognitive capabilities of high functioning individuals on the autism spectrum drawing on theories of psychology and neurology. We present our research that identifies and maps the cognitive style of ASC to skills relevant for software developers to demonstrate a more systematic approach to better utilizing the true unique cognitive style of developers with ASC. Our paper concludes with well-informed strategies to accommodate and foster the strengths of individuals with ASC.

\section{Autism Spectrum Condition Talents Explored}

There is a rich diversity of cognitive abilities and characteristics within the autism population. According to the 5th edition of the Diagnostic and Statistical Manual of Mental Disorders (DSM-V) [1], ASC is a lifelong neurological condition impacting an individual's communication and social abilities, along with restricted behavior, interests, or activities [1]. Sometimes, not always, ASC affects cognitive development [22]. Co-occurring with autism are sensory processing problems, manifesting as sensitivity to sensory stimuli such as sounds and lights [1]. The autism behavioral symptoms are characterized as restricted, repetitive motor movements and restricted interests. An autistic individual may make repetitive motor movements (e.g., body rocking). Restricted interests can manifest as having an intense focus on an interest area, such as trains. This intense focus can impact social interactions and may cause difficulty in establishing diverse relationships [12].

Autism is a spectrum condition encompassing a wide range of severity levels for autism-related symptoms. For instance, along the range of communication, one autistic person can be nonverbal while another autistic person experienced delayed speech. The DSM-V, which is used for medical diagnosis, distinguishes between low functioning autism (LFA) and high functioning autism (HFA) [1]. The DSM-V suggests that high functioning individuals on the spectrum score above-average range on intelligence tests, make up 50\% of individuals on the spectrum, and are the fastest growing sector of the ASC population [22].

\subsection{Hyper-systemizing Theory of Autism}

High functioning individuals with ASC possess unique talents. While there is not a clear agreement on one comprehensive theory to define the cognitive skills of individuals on the spectrum, we draw on a prevailing theory, hyper-systemizing, posited by Simon Baron-Cohen. Baron-Cohen et al [4] suggest that characteristics of autism serve a unique cognitive ability to process a high amount of information in the service of systemizing. We draw on the hypersystemizing theory as opposed to others, namely the executive function [26] and weak central coherence [10] theories of autism, because it is the only theory that attempts to address the cognitive talents of individuals with ASC, which is the focus of our paper.

As Baron-Cohen et al. [4] suggest, high functioning individuals on the spectrum possess a hyper-systemizing cognitive style. They explain that individuals on the spectrum become experts at systemizing; "recognizing repeating patterns in stimuli" to construct systems; rule-based systems in the form of "if $p$ then q" [4, pg. 1377]. Hypersystemizing ability is associated with 1) sensory 
hypersensitivity and 2) hyper-attention to detail. Baron-Cohen et al. [4] posits that individuals with ASC possess a greater sensory perception and memory. This hyper-sensitivity possibly enables individuals with ASC to perceive and process a much higher quantity of information, leading to hyperattention to detail, and ultimately, leading to hypersystemizing. The hyper-systemizing theory differs in that it explains the attention to detail "as highly purposeful: it exists in order to understand a system. Attention to detail is occurring for positive reasons: in the service of achieving an ultimate understanding of a system (however small and specific that system might be)" [4, pg. 1378]. Furthermore, at the neurological level, ASC "involves an abundance of local short-range connectivity" that enables individuals to process a high level of information and connect it to their understanding of the system, one piece at a time. Baron-Cohen [4] suggest that systemizing is a way of predicting outcomes of the system.

The hyper-systemizing theory provides a richer understanding of the true capabilities and limitations of high functioning autistics individuals (refer to Appendix A for a mapping of capabilities and limitations). On the one hand, autistic individuals gain strengths by interpreting the world as a rulebased system, including developing a systems-view of stimuli they receive from the environment [4]. On the other hand, this systemizing requires that a significantly higher timeframe, attention and energy be spent on explaining details, especially when attempting to process a significantly high level of information [4, 19]. Also, the focus on rule based systems makes it difficult for individuals with ASC to adapt to change quickly and, thus, they appear to be rigid [19, 29].

Hyper-attention to details means that individuals with ASC have a great capacity for perceiving and processing information to serve the development of a system view of problems and situations of deep interest [4]. Attention to details however present challenges in regards to time management and narrow interests [11, 19]. Lastly, while sensory hypersensitivity enables individuals on the spectrum to perceive and process larger quantity of information, they often feel anxious and overstimulated [11, 27, 29]. This presents challenges in terms of listening and multi-tasking [19].

The strengths posited by the -systemizing theory and further studies suggest talents beyond attention to details are particularly important for software development, one of many career paths suitable for the talents of HFA individuals. In the next section, we review the need for software developers and the desired skills for software developers.

\section{The Context of Software Development}

The U.S. economy continues to compete for talented software and application developers [13]. According to the Bureau of Labor Statistics, the number of software developer and programmer positions continue to grow, as shown by the trend line in Figure 1. These positions are "expected to add 279,500 jobs by 2022 , accounting for about 4 out of 10 new jobs in the computer and math occupations group" [24]. While programmer jobs are projected to gradually decline by $8 \%$ by 2024 [13]; software developer jobs are growing at a rate of $17 \%$; much faster than average compared to other professional jobs [24]. Consistently, companies are challenged in filling software development positions available due to tough global competition for such talent (Bagley 2014).

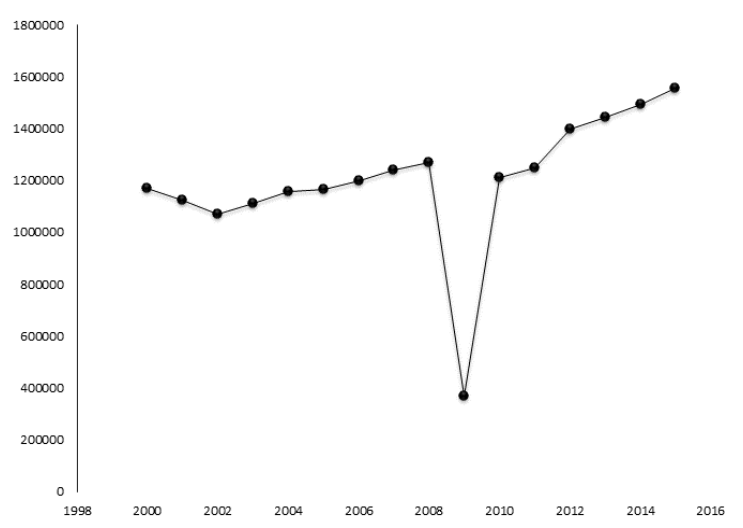

Figure 1. The Number of Software Developers and Programmers in the US (complied from all the years) Source: http://www.bls.gov/oes/tables.htm

Not only is it imperative for tech companies to meet the demand for software talent, they must do so with a diverse pool of developers [2, 8]. To remain relevant, tech organizations must invest in attracting and retaining groups with diverse capabilities, backgrounds, experiences, and skills that lead to greater innovation, better-served consumers, a more skilled workforce, and heightened economic productivity as well as advocating social fairness [9]. Diverse teams consistently outperform even the teams comprising the highest-ability members [18]. Cognitive diversity is especially important in software development [2]. Cognitive diversity leads 
to better problem solving and innovation [2], which is especially important for the complex, ever-changing technology industry.

\subsection{Identifying Cognitive Skills Requirements for Software Developers}

To understand the technology industry's needs for cognitive skills for software developers, we synthesized the skills identified in the current literature and by the U.S. Department of Labor published in the O*NET OnLine repository [20]. Appendix B provides a list and definitions of the skills identified. To confirm the completeness and currency of these skills, we collected and analyzed 20 software development job descriptions from a balanced mix of product and service companies ranging from startups to industry leaders who are engaged in banking, healthcare, ecommerce, consulting and technology products. This exercise was meant to be illustrative rather than comprehensive of the required skills. Our review of the literature and analysis of the job descriptions concluded that the skills required by software developers were broadly categorized as analytical, design, communication, collaboration/relationship and management skills. There is a wide range of skills required across the jobs analyzed. Our analysis revealed that the emphasis was on analytical, teamwork and coordination skills. In terms of analytical skills, programming $(90 \%)$ and problem solving $(60 \%)$ were the two most often listed required skills in job descriptions. Design and modeling was listed in $75 \%$ of job descriptions and coordination and teamwork were listed in $65 \%$ of job descriptions. Figure 2 presents a summary of the skills and their occurrence across the 20 job description.

\subsection{Hyper-systemizing Meets the Range of Analytical Skills for Software Development}

Programming and problem solving were the two most often required analytical skills required for software development. Programming refers to writing computer programs for various purposes. Problem solving involves identifying complex problems, reviewing relevant information to develop and evaluate options, and implementing solutions [15, 16]. Per the hyper-systemizing theory of autism, high functioning individuals on the spectrum have a unique ability to pay attention to detail in the context of complex systems, which are characteristics especially important for programming and problem

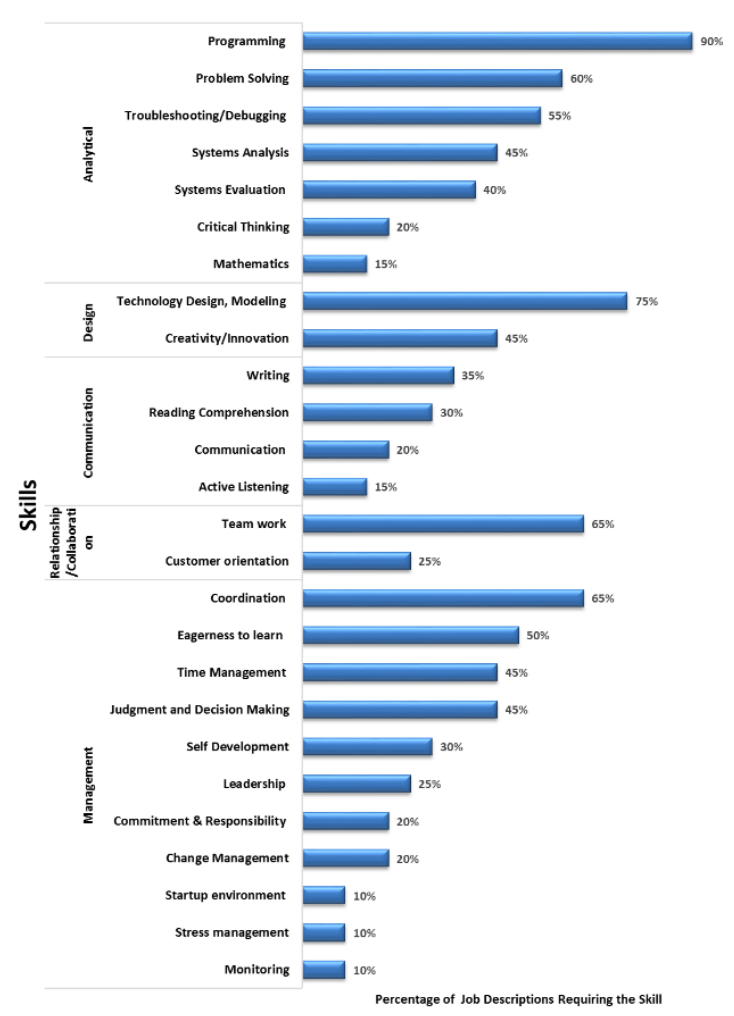

Figure 2. Skills required in 20 representative software development job descriptions.

solving. Further towards suitability for software development is their high level of interest and specialization, consistent with eagerness to learn and ability to make judgment and decisions. Theoretically, one can argue that in light of the hyper-systemizing theory of autism, individuals on the spectrum possess many of the analytical skills required by software developers (programming, math, problem solving, trouble shooting, etc.), perhaps more so than the neuro-typical developer [2, 4].

In light of the hyper-systemizing theory however, individuals on the spectrum will be challenged in terms of some of their communication, management and relationship skills. Individuals on the autism spectrum show narrow interest in other people, have a high need for sameness, and exhibit repetitive behavior that can detract from building relationships and adapting to change [4]. These characteristics in particular can challenge their coordination, teamwork, communication, and leadership skills. Individuals on the spectrum can be most productive when requirements are stable, and work roles and structures are routine and specific [29, 19]. Appendix A provides further detail of the strengths and 
limitations of the cognitive style of ASC posited by the hyper-systemizing theory in relation to software development.

\section{The Way Forward}

The purpose of this paper is to further develop our understanding of the cognitive style of high functioning autistic individuals and map this style to skills relevant for software developers. The unique cognitive style of developers with ASC is clear from our synthesis of the literature. Our analysis, however, suggests that in order to benefit from and enable the further development of the talents of individuals with ASC, firms must adapt to the strengths and accommodate the needs of these developers. There are very few studies focusing on work related topics for HFA [19]. Below is a summary of strategies we identified from the few studies exploring employment and postsecondary transitions.

\subsection{Design roles and responsibilities around ASC strengths and interests}

Our earlier analysis revealed that HFA cognitive style is characterized with a great ability to perceive and process information, pay attention to detail, and systemize. This might also manifest in deep knowledge and narrow interests. Austin and Sonne [2] argue that in order to capitalize on the unique cognitive abilities of ASC, it is important to design roles that may best be served by those skills. They further suggest that job design should be based on a comprehensive understanding of individual capabilities rather than designing roles independent of the abilities and interests of the developers. For this reason, it is also important that ASC developers are not limited to executing small scoped testing roles that only draw on one dimension of their strengths (attention to detail). Morris et al. [19] and Gobb and Shmulsky [11] suggest that matching project and role assignments with the individual's interests to be desirable as well. For most ASC developers, it is key to focus on technical strengths rather than relying solely on interpersonal strengths [19] and to facilitate the exercise and development of interpersonal skills.

\subsection{Design tasks and communicate task level information explicitly}

The hyper-systemizing theory of autism suggests that individuals on the spectrum think systematically. Thus they seek and analyze information in order to recognize and fit information into particular structures. For this reason, it is important that the tasks associated with their roles be structured well and communicated clearly [11,19]. One can argue that individuals with ASC seek structure and thus may be best suited to work under development methodologies that promote stability and regularity than more dynamic and adaptable methodologies. Communication (preferably in writing) and specific articulation of the goals and direction of a project and associated tasks will be key to accommodate and enable ASC developers to contribute and add value in such dynamic environments. Austin and Sonne [2] suggest focusing on short term tasks with individuals with ASC to create clarity of expectation, while communicating when and how tasks will change over time.

\subsection{Design an accommodating work environment}

Sensory hyper-sensitivity creates challenges for individuals with ASC in the workplace. These challenges may be in the form of excessive attention to detail, socializing for long periods, multi-tasking, and over-stimuli $[11,19]$. We suggest that the design of the physical work space for inclusive teams pay particular attention to sensory stimuli, such as noise and the quality of light. Accommodations for ASC developers to have the choice to work in private and telecommute become very important [19]. In the context of meetings and task related interactions, especially group meetings or meetings with managers, ASC individuals may not be able to multitask between taking notes and contributing to conversations. Two strategies to address multitasking challenges are to audio recording meetings or to assign a person to take detailed notes for minutes, which can be distributed to the whole team so as to not single out a particular employee. Morris et al. [19] identified that developers prefer written communication to oral communication when communicating task level detail. Feedback from ASC developers might also be more appropriate and accurate in a written asynchronous fashion to allow them the time needed to process information and make connections.

\subsection{Develop and maintain productive and meaningful inclusive work environment}

Baron-Cohen et al. [4] suggest that ASC individuals tend to have narrow interests, exhibit repetitive and routine behaviors, and resist change. Also, developers with autism find it difficult to interpret nuances in communication and work culture 
[19]. These characteristics makes it challenging to develop relationships with managers and coworkers, leaving individuals feeling isolated. It is important to create stable managerial and team relationships [19]. Gobbo and Shmulsky [11] suggest that managers regularly conduct one-on-one non-judgmental discussions with ASC developers. Peer mentors can play an important role in establishing the tone and culture of understanding and inclusiveness. As well, stigma and ignorance are often associated with ASC, making the environment less welcoming to those with different cognitive and interpersonal characteristics. Training managers and peers on the nature of ASC characteristics is imperative. Training must be accompanied with performance rewards structured to create accountability for inappropriate behaviors towards those on the spectrum.

\section{Conclusion}

In recent years, the technology industry has directed more attention towards employing and onboarding individuals with autism [2, 19]. Many of the employment programs focused on the autism characteristics of attention to detail and repetitive behaviors, and therefore, connected these employees to a limited set of roles including testing, security monitoring and quality assurance (e.g. [2]). In our paper, we suggested expanding our understanding of ASC cognitive skills. We used the hyper-systemizing theory of the cognitive style of HFA to define the strengths of ASC that might be suitable for the technology industry. We also defined the range of skills for software developers to assess how ASC cognitive style may meet the needs for those core skills.

Our analysis of the literature and the skills needed for software developers determined that individuals on the autism spectrum possess important cognitive skills suitable for software development. Most notably, our analysis revealed that ASC leans towards a range of analytical skills (information processes and systemizing) especially suitable for software development. Our analysis also determined that the very same cognitive skills present individuals with ASC may create challenges in terms of managerial, interpersonal, and communication skills. We concluded that to meet the demand for software developers, it is important that firms design roles and work environments that capitalize on the strengths of individuals with ASC and accommodate their needs. There is very little research or knowledge from practice on how to best design roles and inclusive work environments to accommodate employees with
ASC [19]. This conceptual paper provides an introduction to our theoretical understanding of the cognitive style of ASC and strives to inform research aiming at employment of people with ASC in the technology field.

\section{References}

[1] American Psychiatric Association, Diagnostic and statistical manual of mental disorders (5th ed.), Author, Washington, DC, 2013.

[2] Austin, R.D. and Sonne, T., "The Dandelion Principle: Redesigning Work for the Innovation Economy", MIT Sloan Management Review, 55(4), 2014, pp. 67-72.

[3] Baldwin, S., Costley, D., and Warren, A., "Employment Activities and Experiences of Adults with HighFunctioning Autism and Asperger's Disorder", Journal of Autism and Developmental Disorders, 44, 2014, pp. 24402449 .

[4] Baron-Cohen, S., Ashwin, E., Ashwin, C., Tavassoli, T., and Chakrabarti, B., "Talent in autism: Hypersystemizing, hyper-attention to detail and sensory hypersensitivity", Philosophical Transactions of the Royal Society B: Biological Sciences, 364(1522), 2009, pp. 1377 1383. doi:10.1098/rstb.2008.0337

[5] Bergersen, G., \& Sjøberg, D., "Evaluating methods and technologies in software engineering with respect to developers' skill level", 16th International Conference on Evaluation \& Assessment in Software Engineering, 2012. doi:10.1049/ic.2012.0013

[6] Booth, J., "Autism in the Workplace", Trades Union Congress, 2014.

[7] Bornstein, D., "Building a More Inclusive Work Force", New York Times, 2011. Retrieved June 15, 2016 from http://opinionator.blogs.nytimes.com/2011/07/05/buildinga-more-inclusive-work-force/?_r=0.

[8] Cox, T. and Blake, S., "Managing cultural diversity: Implications for organizational competitiveness", Academy of Management Executive, 5(3), 1996, pp. 470-484.

[9] Emerson, J., "Why Diversity Matters to Your Tech Company”, USA Today, 2015. Retrieved June 15, 2016 from

http://www.usatoday.com/story/tech/columnist/2015/07/21/ why-diversity-matters-your-tech-company/30419871/.

[10] Firth, U., “Autism: explaining the enigma”, Basil Blackwell, Oxford, UK, 1989.

[11] Gobbo, K. and Shmulsky, S., "Faculty Experience With College Students With Autism Spectrum Disorders: A Qualitative Study of Challenges and Solutions", Focus on 
Autism and Other Developmental Disabilities, 29(1), 2013, pp. 13-22. doi:10.1177/1088357613504989

[12] Gunn, K. C. and Delafield-Butt, J. T., “Teaching Children With Autism Spectrum Disorder With Restricted Interests: A Review of Evidence for Best Practice", Review of Educational Research, 86(2), 2015, pp. 408-430. Retrieved June 15, 2016 from http://doi.org/10.3102/0034654315604027.

[13] Hogan, A. and Roberts, B., "Occupational Employment Projections to 2024”, Monthly Labor Review, December 2015. Retrieved June 15, 2016 from http://www.bls.gov/opub/mlr/2015/article/occupationalemployment-projections-to-2024.htm.

[14] Lewis, P., Abbeduto, L., Murphy, M., Richmond, E., Giles, N., Bruno, L., \& Schroeder, S., "Cognitive, language and social-cognitive skills of individuals with fragile $\mathrm{X}$ syndrome with and without autism", Journal of Intellectual Disability Research J Intellect Disabil Res, 50(7), 2006, pp. 532-545. doi:10.1111/j.1365-2788.2006.00803.x

[15] Marinovici, C., Kirkham, H., \& Glass, K., "The Hidden Job Requirements for a Software Engineer.” 2014 47th Hawaii International Conference on System Sciences. doi:10.1109/hicss.2014.611

[16] Matturro, G., Raschetti, F., \& Fontan, C. "Soft Skills in Software Development Teams: A Survey of the Points of View of Team Leaders and Team Members", 2015 IEEE/ACM 8th International Workshop on Cooperative and Human Aspects of Software Engineering.

[17] Mazurek, M.O., Shattuck, P.T., Wagner, M., \& Cooper B.P., "Prevalence and correlates of screen-based media use among youths with autism spectrum disorders", Journal of Autism Developmental Disorders, 42(8), 2012, pp. 1757-67.

[18] Mello A.L. and Rentsch J.R., "Cognitive Diversity in Teams: A Multidisciplinary Review”, Small Group Research, 46(6), 2015, pp. 623-658.

[19] Morris, M. R., Begel, A., and Wiedermann, B., "Understanding the Challenges Faced by Neurodiverse Software Engineering Employees: Towards a More Inclusive and Productive Technical Workforce", 2015. Retrieved June 15, 2016 from http://dx.doi.org/10.1145/2700648.2809841.

[20] National Center for O*NET Development, "Skills Search, O*NET Online, Retrieved June 11, 2016 from https://www.onetonline.org/skills/.

[21] Orsted, M. "Software development engineer in Microsoft. A subjective view of soft skills required", Proceedings of the 2000 International Conference on Software Engineering, ICSE 2000 the New Millennium.
[22] Pinder-Amaker, S., "Identifying the Unmet Needs of College Students on the Autism Spectrum", Harvard Review of Psychiatry, 22(2), 2013, pp. 125-137.

[23] Pfleeger, S. "What software engineering can learn from soccer”, IEEE Softw. IEEE Software, 19(6), 2002, 64-65. doi:10.1109/ms.2002.1049393

[24] Richards, E. and Terkanian, D., "Occupational Employment Projections to 2022”, Monthly Labor Review, December 2013. Retrieved June 15, 2016 from http://www.bls.gov/opub/mlr/2013/article/occupationalemployment-projections-to-2022.htm.

[25] Roux, A. M., Shattuck, P. T., Rast, J. E., Rava, J. A., and Anderson, K. A., "National Autism Indicators Report: Transition into Young Adulthood", Life Course Outcomes Research Program, A.J. Drexel Autism Institute, Drexel University, Philadelphia, PA, 2015. Retrieved June 15, 2016 from http://drexel.edu/autismoutcomes/publicationsand-reports/publications/Employment-Outcomes-ofYoung-Adults-on-the-AutismSpectrum/\#sthash.xFIqvpm6.dpuf.

[26] Rumsey, J.M. and Hamberger, S.D., "Neuropsychological findings in high functioning men with infantile autism, residual state", Journal of Clinical and Experimental Neuropsychology, 10, 1988, pp. 201-221.

[27] Seltzer, M. M., Krauss, M. W., Shattuck, P. T., Orsmond, G., Swe, A., and Lord, C., "The Symptoms of Autism Spectrum Disorders in Adolescence and Adulthood", Journal of Autism and Developmental Disorders, 33(6), 2003, pp. 565-581. doi:10.1023/b:jadd.0000005995.02453.0b

[28] Shattuck, P.T., Narendorf, S.C., Cooper, B., Sterzing, P.R., Wagner, M. and Taylor, J.L., "Postsecondary Education and Employment Among Youth With an Autism Spectrum Disorder", Pediatrics, 129(6), 2012.

[29] Trevisan, D. and Birmingham, E., "Examining the relationship between autistic traits and college adjustment", Autism, October 15, 2015. doi:10.1177/1362361315604530

[30] Valentin, E., Carvalho, J. R., \& Barreto, R., "Rapid improvement of students' soft-skills based on an agileprocess approach" 2015 IEEE Frontiers in Education Conference (FIE). doi:10.1109/fie.2015.7344408

[31] Wang, S.S., "How Autism Can Help You Land a Job: SAP, Freddie Mac Recruit Autistic Workers to Fill Roles that Call for Precision; Debugging Software", The Wall Street Journal, March 27, 2014. Retrieved June 11, 2016 from

http://www.wsj.com/articles/SB1000142405270230441840 4579465561364868556.

[32] Wei, X., Christiano, E.R.A., Yu, J.W., Blackorby, J., Shattuck, P., and Newman, L.A., "Postsecondary Pathways 
and Persistence for STEM Versus Non-STEM Majors:

Among College Students with an Autism Spectrum
Disorder", Journal of Autism and Developmental Disorders, 44, 2014, pp. 1159-1167.

\section{Appendix A. Hyper-systemizing Theory of ASC Cognitive Style [4]}

\begin{tabular}{|c|c|c|c|c|}
\hline $\begin{array}{l}\text { Cognitive } \\
\text { Style }\end{array}$ & $\begin{array}{l}\text { Strength } \\
\text { Implications }\end{array}$ & $\begin{array}{l}\text { Weakness } \\
\text { Implications }\end{array}$ & $\begin{array}{l}\text { Relevance to } \\
\text { Software } \\
\text { Development } \\
\end{array}$ & Strategies \\
\hline \multirow[t]{3}{*}{$\begin{array}{l}\text { Hyper- } \\
\text { systemizing }\end{array}$} & $\begin{array}{l}\text { Rule-based system: } \\
\text { Input-operation- } \\
\text { output [4] } \\
\text { Adherence to rules } \\
\text { and standards [11, } \\
\text { 19] }\end{array}$ & $\begin{array}{l}\text { Resistant to change } \\
{[19,29]}\end{array}$ & $\begin{array}{l}\text { View of software as } \\
\text { a system of } \\
\text { interrelated parts [4] } \\
\text { Strict adherence to } \\
\text { coding style and } \\
\text { guidelines [2] }\end{array}$ & $\begin{array}{l}\text { Provide a structured layout } \\
\text { for work [11] } \\
\text { Assign responsibility for } \\
\text { code review }[2,19]\end{array}$ \\
\hline & $\begin{array}{l}\text { System view: } \\
\text { associations of } \\
\text { rules in the context } \\
\text { of a system }[4,14]\end{array}$ & $\begin{array}{l}\text { Have a specific } \\
\text { routine behavior } \\
\text { and can become } \\
\text { rigid [29] }\end{array}$ & $\begin{array}{l}\text { Complete tasks } \\
\text { assigned } \\
\text { [19] }\end{array}$ & $\begin{array}{l}\text { Assign as devil's advocate } \\
\text { role and peer review of } \\
\text { code }\end{array}$ \\
\hline & $\begin{array}{l}\text { Recognize } \\
\text { repeating pattern } \\
{[19]}\end{array}$ & $\begin{array}{l}\text { Repetitive behavior } \\
{[4,27,29]}\end{array}$ & Spot bugs [2] & $\begin{array}{l}\text { Assign work items which } \\
\text { involve recognizing } \\
\text { patterns. }\end{array}$ \\
\hline \multirow[t]{2}{*}{$\begin{array}{l}\text { Hyper- } \\
\text { attention to } \\
\text { detail }\end{array}$} & $\begin{array}{l}\text { Excellent attention } \\
\text { to detail [11] }\end{array}$ & $\begin{array}{l}\text { Challenge in time } \\
\text { management [19] } \\
\text { Can stifle } \\
\text { innovation [18] }\end{array}$ & $\begin{array}{l}\text { Review code } \\
\text { Conduct } \\
\text { walkthrough } \\
{[2]}\end{array}$ & $\begin{array}{l}\text { Provide a structured } \\
\text { guidelines and schedule of } \\
\text { the project plan with } \\
\text { detailed description of } \\
\text { work items. }\end{array}$ \\
\hline & $\begin{array}{l}\text { In depth } \\
\text { knowledge/passion } \\
\text { ate interest [11] }\end{array}$ & $\begin{array}{l}\text { Narrow interests } \\
\text { ("See the parts not } \\
\text { the whole" - [11] }\end{array}$ & $\begin{array}{l}\text { Out of the box } \\
\text { thinking } \\
\text { [19] }\end{array}$ & $\begin{array}{l}\text { Allow to work on strength } \\
{[11,19]}\end{array}$ \\
\hline \multirow[t]{2}{*}{$\begin{array}{l}\text { Sensory hyper- } \\
\text { sensitivity }\end{array}$} & \multirow[t]{2}{*}{$\begin{array}{l}\text { Sensory } \\
\text { hypersensitivity: } \\
\text { Perceive and } \\
\text { Process a large } \\
\text { quantity of } \\
\text { information from } \\
\text { multiple sensory } \\
\text { modes [4] }\end{array}$} & $\begin{array}{l}\text { Challenges in inter- } \\
\text { personal } \\
\text { communication } \\
\text { (especially } \\
\text { synchronous), } \\
\text { results in anxiety } \\
{[11,27,29]}\end{array}$ & & $\begin{array}{l}\text { Focus on Strengths }[4,11, \\
19] \\
\text { Create a platform to share } \\
\text { the design and code } \\
\text { feedback in asynchronous } \\
\text { mode such as mail/online } \\
\text { tools. }\end{array}$ \\
\hline & & $\begin{array}{l}\text { Challenges } \\
\text { listening and multi- } \\
\text { tasking [19] }\end{array}$ & & $\begin{array}{l}\text { Assign other team } \\
\text { members to take notes. } \\
\text { Train managers to reiterate } \\
\text { the meeting minutes and } \\
\text { clarify items with adequate } \\
\text { details }[11,19]\end{array}$ \\
\hline
\end{tabular}




\section{Appendix B. Software Developer Skills}

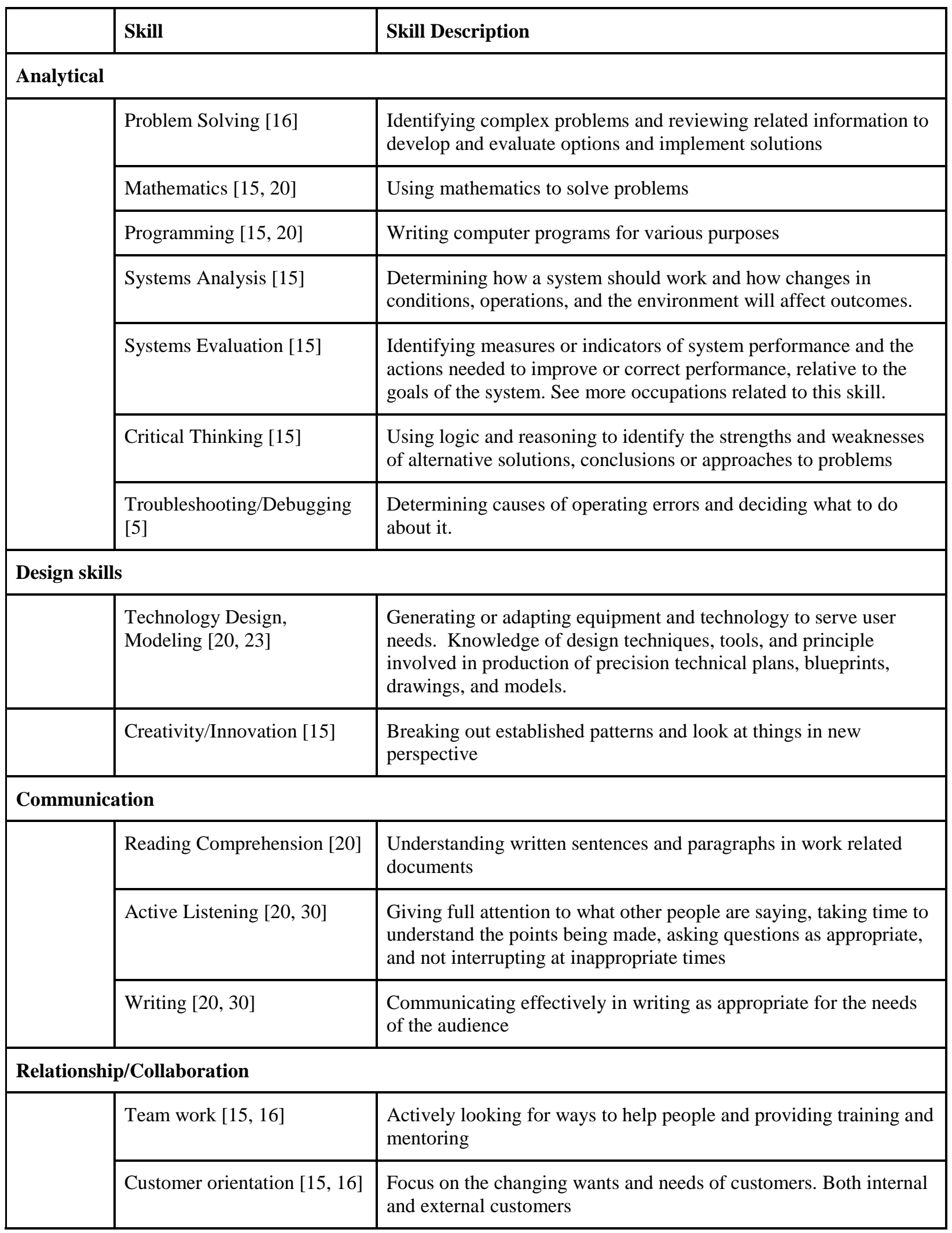




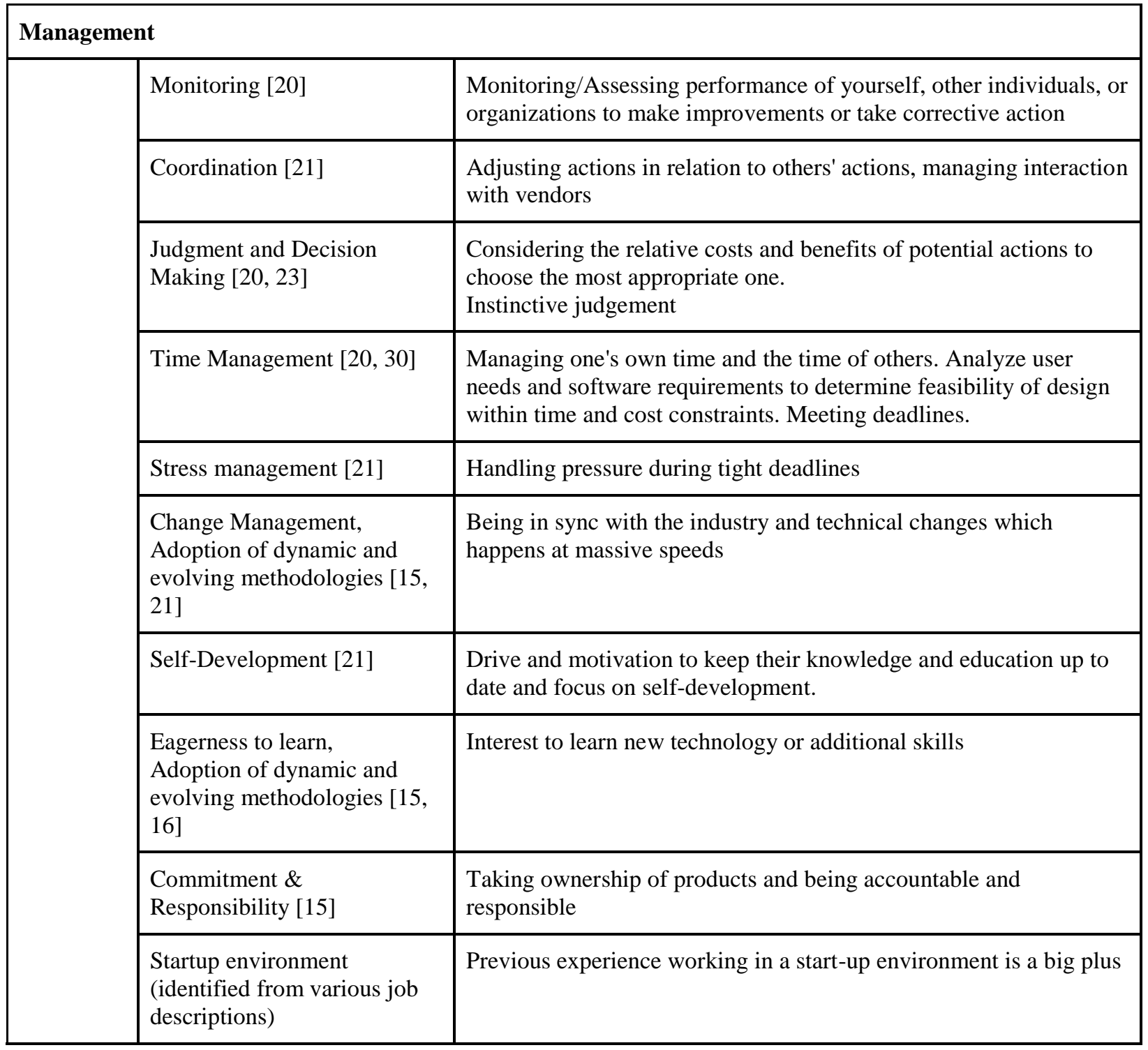

